\title{
Transhumanism and Evolution. Considerations on Darwin, Lamarck and Transhumanism ${ }^{1}$
}

Filip Bardziński (Adam Mickiewicz University, Poznań)

\section{The Origins of Transhumanism}

Almost a decade has passed since Nick Bostrom explained that transhumanism "holds that current human nature is improvable through the use of applied science and other rational methods, which may make it possible to increase human health-span, extend our intellectual and physical capacities, and give us increased control over our own mental states and moods" (Bostrom 2005a, 202-203). Ultimately, Bostrom believed that such changes in human nature could "make us, or our descendants, "posthuman", beings who may have indefinite health-spans, much greater intellectual faculties than any current human being - and perhaps entirely new sensibilities or modalitiesas well as the ability to control their own emotions" (Bostrom 2005a, 203). In general, Bostrom, as well as other researchers such as Ingmar Persson, Rebecca Roache, Julian Savulescu, Mark A. Walker, dedicated their work to understanding, developing, and establishing the notion of transhumanism not only as “a man's responsibility and destiny-to be an agent for the rest of the world in the job of realizing its inherent potentialities as fully as possible" (Huxley 2015, 12), but rather to transcend these inherent potentials through such interventions that will result in attaining "at least one posthuman capacity, [that is] a general central capacity greatly exceeding the maximum attainable by any current human being" (Bostrom 2008, 107). The posthuman goal is thus not to achieve perfection in any biologically or socially given way, but rather to overcome species-based limitations.

The desire to enhance certain human qualities and abilities is, according to Bostrom, not an idea born of today; the Swedish philosopher traces its roots to the Sumerian Epic of Gilgamesh, ancient burial ceremonies, and the search for the Fountain of Youth and the Philosopher's Stone. All of the aforementioned were aimed at extending life or attaining biological immortality. As Bostrom noted, the thirst for eternal youth is inborn in human nature: "The human desire to acquire new capacities is as ancient as our species itself. We have always sought to expand the boundaries of our existence, be it socially, geographically, or mentally" (Bostrom 2005b, 1). These desires have been elaborated in two different ways: On the one hand,

${ }^{1}$ The writing of this article was funded by the Polish National Science Centre NCN (Dec-2013/10/E/HS5/00157). 
we have the bioconservative notion of transcending one's physical or mental limitations through training, education, self-assessment and self-development. This is made possible through the ability to transcend one's self by recognizing others as free and equal subjects: "Persons can therefore differentiate between their nature and themselves; they can transcend themselves; they can overcome self-centredness... . Unlike animals, which cannot pass judgement on their own natural appetites and cannot choose whether to behave in accord with them or not, the nature of persons is not identical to their being a person" (Zaborowski 2010, 199). In effect, as stated already by Bostrom, within human nature lies the need to "become something more"; however, in opposition to the transhumanist view, this development does not take place on the biological plane, but instead has a metaphysical meaning. It thus requires not technological interventions, but self-control and self-development techniques, which are concentrated on the mental-spiritual nature of humans.

On the other hand, transhumanists argue, it is impossible to actually attain the aforementioned goals-a longer lifespan, and better physical, mental, or moral capabilities-without referring to scientific (specifically, biological and medical) means. Putting it simply: "You will never turn a Chihuahua into a Doberman through grooming, training and affection" (Savulescu 2005, 36). The development of genetics, neurosciences, and medicine prove that there are significant genetic foundations for most human capabilities and traits. We have known since the mid-1980s that there are correlations between genes and aggressive behaviour; it would thus be difficult for some to overcome their characters flaws without any kind of medical aid. Therefore, it would be unwise-and unfair-to leave to chance and the "genetic lottery" the possibility of developing one's capabilities if a safe and trustworthy technique (e.g., genetic engineering) could ameliorate one's chances of having a satisfying life, or offer the possibility of choosing from a multitude of given possibilities (see: Savulescu 2001; Agar 1998). As such, transhumanists draw their roots from the Darwinian (but also, to some small extent, from the Galtonian) paradigm in the natural sciences.

\section{Darwin's Theory of Evolution}

The evolution of the human species - and for all species, in fact - proceeds without a given goal or aim. The only logic evolution follows is that of natural selection, which may be summarised as follows: "If environmental conditions are static, effects of breeding are constant, the species persists in multiple generations, then such a fraction of the species will spread, which maximises the adaptation criterion in the given environment" (Łastowski 2004, 77). This theorem may be further elaborated in Darwinian terms to the theorems of directionally and fractionally balancing selection. The Darwinian theory of 
evolution has been further developed by, among others, J. B. S. Haldane, Theodosius Dobzhansky, and Ernst Mayr, finally assuming the form of modern evolutionary synthesis.

What is important to note is the fact that the subject of natural selection is not the individual, but the species. The mechanism of evolution may thus be described as follows: In a certain environment, the fractions that adapt to given conditions given outlive and have fertile offspring, while those that do not adapt to conditions will become extinct. The Darwinian theory of evolution thus aims to explain the origins of species, but does not provide any methodological frame for explaining how an individual adapts to changing environmental conditions. Transhumanism, however, while deeply rooted in the Darwinian understanding of evolutionary biology, values highly the individualistic notion of personal liberties and happiness. Such a combination may thus prove difficult to maintain.

\section{Transhumanism and Darwin's Theory of Evolution}

It is possible to trace a common point in the Darwinian and transhumanist perceptions of the forces of evolution. As pointed out by Charles T. Rubin:

Transhumanism rebels against the randomness of evolution ... But ... transhumanism builds on the very same underlying conception of nature that the Malthusians and Darwinians build on, vociferously rejecting the thought that nature has any inherent normative goals or purposes. While it rejects blind evolution as a future fate for man, it accepts it as the origins of man. ... Transhumanism is a nihilistic response to the nihilism of the Malthusians and Darwinians (Rubin 2014).

This claim may be further illustrated if we acknowledge the fact that some proponents of human genetic enhancement draw their roots from nineteenthcentury eugenic claims. As Nicholas Agar wrote in 1998: "Recent advances in the understanding of human heredity offered by the new genetics have prompted a revival in eugenics" (Agar 1998, 137). The assumed restoration of eugenics, improved through a liberal account, is being accomplished through Darwinian means: the impact the parental generation may have on filial generations.

At this point, the transhumanist claim may seem legible in light of the Darwinian theory of evolution. What transhumanists wish to achieve is, inter alia, the eradication of diseases of genetic origin (especially single-gene disorders, as it is possible to precisely identify the allele responsible for the disease), extending human lifespan, etc. These goals are, in light of the Darwinian theory of evolution, not only goods in themselves, but also means to an end: the chance to have fertile offspring. We may safely assume that such features as long life, general healthiness (or at least being free of genetic 
diseases), mental stability, generally raise the chances of having a satisfying life, but also fall easily under the Darwinian logic of evolution.

The two benefits derived from the transhumanist enhancement of human capacities are worth elaborating. As explained by Savulescu, it is generally worthwhile to pursue such means of enhancement that will enable parents to "select the child, of the possible children they could have, who is expected to have the best life, or at least as good a life as the others, based on the relevant, available information" (Savulescu 2001, 413). The possibility to lead the best possible life does not imply any kind of specific, finite capacities; it rather implies that some of them do increase the chance of having a fulfilling life, and some do not. Thus, it is our moral obligation to select accordingly to a principle that will maximize the probability of our future children being able to lead a good life. Traits that may have a positive impact on such possibilities include a longer lifespan, healthiness, mental and cognitive stability, and many others. Obviously, since there is no general recipe for a good life, there is no general recipe for what traits should be chosen; this implies that the coming generations will not become uniformed societies of look- and think-alikes. Rather, the multitude of possible "good lives" will sustain diversity-in the biological sense, as well.

On the other hand, the aforementioned traits are not culturally-based, but have a significant biological content. Thus, they partake in the great scheme of evolution of species on Earth. It would be advisable to try to reassess whether such interference in human genetics does not entail risks in which we-as a society and a species-would not agree to partake. Probably the most common objection to human enhancement by genetic means is that it may disrupt the universal model of heredity as a lottery, and replace it with planning and production logic. Such determination may have a damaging impact on both the generational relations in societies, as well as on selfunderstanding and self-consciousness. This objection has been formulated notably by Jürgen Habermas: "Irrespective of how far genetic programming could actually go in fixing properties, dispositions, and skills, as well as in determining the behaviour of future person, post factum knowledge of this circumstance may intervene in the self-relation of the person, the relation to her bodily or mental existence" (Habermas 2003, 53). It is possible to dismiss easily such claims by stating that human enhancement does not aim at determining anything except a broader horizon of available life possibilities. Transhumanists do not wish to promulgate a society of Mozarts and Einsteins; their aim is to make such talents (or rather: physical, mental, and cognitive capacities) available to all. An enhanced person is not "programmed to triumph"; s/he could still choose not to develop any kind of ability or talent and pursue a mediocre life; what s/he however would be entailed is the sheer possibility to make such a choice without biological limitations. Thus, no harm is being done to one's personal understanding or bodily self-relation. 
On this account, we may ascertain that it would be possible for at least some of those being enhanced to actually exceed human biological nature and become the founders of a new species: the posthuman. As observed by Bostrom, there are some obvious limitations to this perspective: some modes of posthuman being are not worthwhile to pursue and some may in fact be dangerous. Still, it is advisable to follow a course of action that would enable us to live a posthuman life. This course of action demands we embrace technological progress and make available all its achievements to both individuals (self-enhancement) and prospective parents (future child enhancement). At this point, it becomes visible that the reluctance towards the "natural genetic lottery" that is often expressed by transhumanists does in fact somehow support the "production" logic of which they are accused by Habermas. As noted by Bostrom: "The horrors of nature in general, and of our own nature in particular, are so well documented that it is astonishing that somebody ... should still in this day and age be tempted to rely on the natural as a guide as to what is desirable or normatively right" (Bostrom 2005a, 205). A broad comment can be made regarding Bostrom's remark.

Firstly, Bostrom seems not to acknowledge the difference between what is desirable and what is normatively right. To admit that what is natural is normatively right is-obviously-a claim that is difficult to maintain. The aforementioned notion of genetic correlations of aggressive behaviour may be utilised to excuse or justify, in some cases, such actions and attitudes. However, it would be impossible to maintain that such a correlation has a normative value: aggressive behaviour may have been a valuable capacity for survival in unfriendly and highly competitive environments. Since humans obtained the capacity to reflect, it is untenable for human species to maintain such an attitude, as the ability to think, plan, and cooperate have proven to be even better for maximising chances to adapt (see: Sussman, Garber, \& Cheverud 2005). On the other hand, it is possible to admit that, in certain cases, acting in an aggressive manner would be desirable. Desirable traits and capacities may not fit into any kind of normativity, which does not mean we would not perceive them as desirable. As observed by Robert Spaemann: "We have to personally want to draw even the most obvious conclusions" (Spaemann 2012, 194). Thus, it is possible to conclude that we may simultaneously affirm that, although we do desire some of them for reasons other than moral, certain traits and capacities, originating from the natural constitution of human species, do not fall into any normative order.

It is still possible, however, to make a more subtle, yet equally important remark from the standpoint of Darwinian evolution. As stated earlier, the basic and unique rule of Darwinian evolution is natural selection: those factions of a species which maximise their adaptation to existing conditions, will endure and have fertile offspring; other factions will, consequently, become extinct. If we take this theorem seriously, we can see 
the point at which the paths of the theory of evolution and transhumanism diverge. At the core of Darwinian evolution is the notion of species, while transhumanists place an emphasis on the individual as both the subject and object of enhancement. Thus, although Darwin believed that it is speciation and selection that produce species, transhumanists seem to believe that through individual adaptation we may also arrive at the creation of a new species.

We may develop the above statement as follows: when talking about the aims of the transhumanist movement, as noted earlier, Bostrom evokes that "transhumanism is a loosely defined movement that ... promotes an interdisciplinary approach to understanding and evaluating the opportunities for enhancing the human condition and the human organism opened up by the advancement of technology" (Bostrom 2003, 493). We may safely assert that the aim of Bostrom's enhancement takes into account the condition of the human species as a whole. What Bostrom acknowledges even further is the biological and taxonomic dissimilarity between organisms that fall into the two categories: the human and the posthuman. The mechanism that makes it possible to achieve such dissimilation (and thus may be seen as the origin of a new species) is-for Bostrom and Savulescu-the availability of technological tools for enhancing either oneself directly or one's future offspring. As Bostrom writes:

Transhumanists promote the view that human enhancement technologies should be made widely available, and that individuals should have broad discretion over which of these technologies to apply to themselves (morphological freedom), and that parents should normally get to decide which reproductive technologies to use when having children (reproductive freedom) (Bostrom 2005a, 203).

Although differing in their respective subjects, the right to enhance oneself, and the right to enhance future offspring, are thus in fact two possible notions of a more general account of personal freedoms.

Savulescu develops further the latter notion (of reproductive freedom) by reshaping it into a more general "moral obligation to enhance our children's lives and opportunities" through means of "genetic selection" (Savulescu 2005, 37). At this point of technological development, Savulescu argues, we are inclined to apply all possible means that would augment the chances of future generations to live a better life, even if it means transcending human nature and venturing into the new realm of posthumanity. Posthumanity is thus an evolutionary necessity, which seems to even further maximise humanity's adaptability through steering its own biological evolution: "Current humanity need not be the endpoint of evolution" (Bostrom 2003, 493). 
The posthumanist scheme of "steering evolution" is thus attained through means that are designed to impact individuals selectively. The notion of utilising genetic selection and engineering, as well as other technological means, is applicable to individuals only in two senses: Firstly, it is morally unacceptable to think of a global, general, state-planned mechanism of enhancement, as it would inevitably fall into the fallacies of early-twentieth century eugenics programme: "Old fashioned authoritarian eugenicists sought to produce citizens out of a single centrally designed mould, the distinguishing mark of the new liberal eugenics is state neutrality. ... Authoritarian eugenicists would do away with ordinary procreative freedoms. Liberals instead propose radical extensions of them" (Agar 1998, 137). Secondly, it is precisely the concept of reproductive freedom, originating in the concept of human rights (see: Freedman \& Isaacs 1993), that creates the theoretical mainframe for human enhancement discussions.

In sum, transhumanists seem to believe in the possibility of creating a new species through individual decisions for enhancement. This view, however, is not supported by the Darwinian theory of evolution, which, as has already been stressed, takes a broader perspective on how species as a whole react to changing (or stable) environmental conditions. These reactions are then "evaluated" through the mechanism of natural selection, which is then either the origin of a species (those already existing or truly new ones) or its demise. For Darwin and his successors, there is few or no attention whatsoever given to the question of how individuals react to their environment and how they adapt on the individual level to stress and other factors. This is precisely the point at which the Darwinian understanding of evolution and the transhumanists part ways-to the disadvantage of the latter, it seems.

\section{Transhumanism and Lamarckism}

The transhumanist perspective on evolution, however-understood in terms of individual change and adaptation-is not new. At the turn of the eitheenth and nineteenth centuries, the French naturalist Jean-Baptiste de Lamarck wrote his classic work Zoological Philosophy: Exposition with Regard to the Natural History of Animals, in which he developed an alternative to the Darwinian concept of the evolution of living beings. His theory may be summarised in three general concepts: "(1) the notion of degradation; (2) issue of the definition of a «species»; (3) the concept of transmutation, or evolution" (Łastowski 2009, 259), the latter of which was based on two notions: that of heredity, and that of adaptation: "The first one refers to relations, that occur between breeding individuals; the second asses the reaction of individuals to the requirements of the life conditions" (Łastowski $2004,65)$. These two factors do not act separately, but instead have a 
complimentary impact on living beings. Thus, evolution, according to Lamarck, is an "interplay between two powerful factors: the innate heritability of characteristics acquired under the influence of the environment (l'influence des circonstances) and a certain immanent force pulling living nature towards greater complexity and higher adaptability (le pouvoir de la vie) as the cumulative driver of evolution" (Gadjev 2015, 242-243). The notion of heredity, as Lamarck believed, may be summarised by stating that the offspring acquires the average of the traits of its parents. In consequence, if living conditions remain neutral, "in a pangenetic system of breeding the diversity of individuals declines over generations, and the similarity between individuals grows" (Łastowski 2009, 261). However thoroughly developed, Lamarck's theory of evolution has proven to be false, and its main concepts generally dismissed by the science community. Still, as noted by A. Van Soom and his collaborators:

Although Lamarckism fell out of favour soon after the publication of Darwin's work on natural selection and evolution, the concept of transmission of acquired characteristics has recently gained renewed attention and has led to some rethinking of the standard evolutionary model. Epigenetics, or the study of heritable (mitotically and/or meiotically) changes in gene activity that are not brought about by changes in the DNA sequence, can explain some types of ill health in offspring, which have been exposed to stressors during early development, when DNA is most susceptible to such epigenetic influences (Van Soom et al. 2014, 2).

Acknowledging the existence of epigenetic mechanisms may have an impact on transhumanists claims-an impact that is difficult to discuss, as these mechanisms are still not fully understood, and the transhumanists' claims are far from being unanimously approved.

Lamarckism has proven, however, to be a satisfactory mode of explanation in a different context: the cultural evolution of humanity. As observed by Stephen J. Gould:

By analogy only, it is the mode of »inheritance« for another and very different kind of »evolution «-human cultural evolution. ... Homo sapiens arose at least 50,000 years ago, and we have not a shred of evidence for any genetic improvement since then. ... we have transformed the surface of our planet through the influence of one unaltered biological invention-self-consciousness ... without substantial genetic change (Gould 1980, 83).

Yet, transhumanists would refuse to admit that the enhancement they advocate is of cultural origin and does not constitute traits that are valuable only in a cultural context: "When we say that [health] is valuable we might merely mean that this thing would normally make a positive contribution to the value of your life ... This mundane meaning is what I have in mind when I 
speak of modes of [posthuman] being having a value" (Bostrom 2008, 110). Posthuman capacities and traits, according to Bostrom, are generally valuable, and thus not context-dependent.

What makes the transhumanist perspective close to the Lamarckian concept of evolution is precisely its focus on the individual as the main actor in evolutionary processes and on individualistic ways of adapting to given conditions as fuelling evolutionary change. These notions however, as stated earlier, are of no real significance in either Darwinian or modern neoDarwinian theories of evolution. In effect, we may assert the existence of a dangerous gap between the transhumanist vision of evolution (and thus how to impact or steer it) and biological knowledge of these processes. Such a gap obviously does not favour a favourable reading of transhumanist proposals by biologists, physicians, and other members of the natural sciences, which is crucial for the success of posthumanity.

\section{Success Comes at a Price}

We can make a further remark on the ideals to which transhumanists aspire, based on recent findings in molecular biology and genetics. A complex study led by Joel Dudley revealed that certain parts of our genome, called human accelerated regions, or HARs, ${ }^{2}$ may incline individuals to develop schizophrenia. Both schizophrenia and HARs appear to be, for the most part, human-specific. What is more, schizophrenia-related genes sit close to HARs along the human genome. Furthermore, it was revealed that HAR-associated schizophrenia genes were under stronger evolutionary selective pressure than other schizophrenia genes. This observation implies that the human variants of these genes are essential to us in some way, despite the risks they harbour. The study led by Dudley and collaborators found that HARassociated schizophrenia genes are found in regions of the genome that influence other genes expressed in the prefrontal cortex, a brain region just behind the forehead that is involved in higher-order thinking. Impaired function in the prefrontal cortex is thought to contribute to psychosis. They also found that these culprit genes are involved in various key human neurological functions within the prefrontal cortex (see: Xu et al. 2015; Stetka 2015).

The conclusions derived from these findings will inevitably vary. Some may assume that the possible genetic link between high-order thinking and schizophrenia somehow confirms the colloquial stereotype that links

2 "Human accelerated regions (HARs) are DNA sequences that changed very little throughout mammalian evolution, but then experienced a burst of changes in humans since divergence from chimpanzees. This unexpected evolutionary signature is suggestive of deeply conserved function that was lost or changed on the human lineage" (Hubisz \& Pollard 2014, 15). 
greatness of some kind (specifically-high cognitive capabilities that are the basis for acknowledging someone as being a genius) with some sort of brain dysfunction-this belief having been proven false. Some may see this finding as an opportunity for better understanding the mechanisms involved in the development of schizophrenia. The findings of Dudley et al. may, however, be of importance in relation to transhumanist claims.

In assuming that it is worthwhile to provide both ourselves and our future children with greater cognitive abilities (those including better memory, greater capacity to do elaborated analysis, and others), we assert that these enhancements should come with an acceptable level of risk. These risks would include the possibility of technically failing to achieve what was intended (i.e., enhancement technologies being abused), but also, and more importantly, the possibility of outcomes that are harmful rather than liberating. If such a reservation is being made-and we have in mind the broad horizon of species evolution-we may arrive at the disturbing conclusion that while it is impossible to steer our species' evolution in a harmful manner, it is difficult to actually assess all the possible risks of genetic engineering and other enhancement technologies. As for genetic enhancement, it is worthwhile recalling that although "our fate is written rather in genes than in the stars," it is not a single gene but a constellation of genes that are "coupled together with other genes, in their closest vicinity; but also distant ones, from far-lying chromosomes" (Szczeklik 2003, 28). Thus, it may prove difficult to evaluate with a satisfactory degree of precision all possible risks and dangers. An analogous claim may be made towards other enhancement techniques: They would probably not truly augment our capabilities, but rather prove to be only mere gadgets, as none of them would actually impact our biological, evolutionary-determined condition.

\section{Conclusion}

Evolution does not stop or take any breaks. Although it may seem like an utopian dream to finally achieve some degree of control over evolution such a claim will remain impossible for a simple reason: If we wish to impact the biological evolution of the human species, we would have to do so through a global and uniformed programme, closely resembling state-driven eugenics. The measures being advocated by transhumanists would thus be ineffective and only lead to achieving short-term and short-ranged effects, which would probably not satisfy the demands and ambitions relating to transhumanism. 


\section{References}

Agar, N. 1998. "Liberal Eugenics." Public Affairs Quarterly 12 (2): 137-155.

Bostrom, N. 2003. "Human Genetic Enhancements: A Transhumanist Perspective." The Journal of Value Inquiry 37 (4): 493-506.

_- - 2005a. "In Defense of Posthuman Dignity." Bioethics 19 (3): 202-14.

- - . 2005b. "A History of Transhumanist Thought." Journal of Evolution and Technology 14 (1): 1-25.

Freedman, L. P. \& Isaacs, S. L. 1993. "Human Rights and Reproductive Choice." Studies in Family Planning 24 (1): 18.

Gadjev, I. 2015. "Nature and Nurture: Lamarck's Legacy." Biological Journal of the Linnean Society 114 (1): 242-47.

Gould, S. J. 1980. The Panda's Thumb: More Reflections in Natural History. New York: Norton.

Habermas, J. 2003. The Future of Human Nature. Cambridge: Polity.

Hubisz, M. J. \& Pollard, K. S. 2014. "Exploring the Genesis and Functions of Human Accelerated Regions Sheds Light on Their Role in Human Evolution." Current Opinion in Genetics \& Development 29: 15-21.

Huxley, J. 2015. "Transhumanism". Ethics in Progress 6 (1): 12-16.

Łastowski, K. 2004. "Lamarck i Darwin. U podstaw idei ewolucji." In: Łastowski, K. (Ed.), Teoria i metoda $w$ biologii ewolucyjnej. Poznań: Wydawnictwo Zysk i S-ka.

———. 2009. "Dwieście lat idei ewolucji w biologii: Lamarck - Darwin Wallace". Kosmos. Problemy nauk biologicznych 58 (3-4): 257-71.

Rubin, Ch. T. 2014. Eclipse of Man: Human Extinction and the Meaning of Progress. New York: Encounter Books.

Savulescu, J. 2001. "Procreative Beneficence: Why We Should Select the Best Children." Bioethics 15 (5-6): 413-26.

- - . 2005. "New Breeds of Humans: The Moral Obligation to Enhance." Reproductive BioMedicine Online 10 (January): 36-39.

Spaemann, R. 2012. Kroki poza siebie: Przemówienia i eseje. Trans. J. Merecki. Warszawa: Oficyna Naukowa.

Stetka, B. 2015. "Schizophrenia May Be the Price We Pay for a Big Brain." Scientific American Mind 26 (4).

Sussman, R. W., Garber, P. A., \& Cheverud, J. M. 2005. "Importance of Cooperation and Affiliation in the Evolution of Primate Sociality." American Journal of Physical Anthropology 128 (1): 84-97.

Szczeklik, A. 2003. Katharsis: $O$ uzdrowicielskiej mocy natury i sztuki. Kraków: Znak.

Van Soom, A, Peelman, L., Holt, W. V., \& Fazeli, A. 2014. "An Introduction to Epigenetics as the Link Between Genotype and Environment: A Personal View." Reproduction in Domestic Animals 49 (September): 210. 
Xu, K., Schadt, E. E., Pollard, K. S., Roussos, P., \& Dudley, J. T. 2015. “Genomic and Network Patterns of Schizophrenia Genetic Variation in Human Evolutionary Accelerated Regions." Molecular Biology and Evolution 32 (5): 1148-1160.

Zaborowski, H. 2010. Robert Spaemann's Philosophy of the Human Person: Nature, Freedom, and the Critique of Modernity. Oxford: New York: Oxford University Press. 
Filip Bardziński (Poznań)

Transhumanism and Evolution. Considerations on Darwin, Lamarck, and Transhumanism

\begin{abstract}
In the paper, I discuss the possible gap between the transhumanist perspective of controlling and perfecting human evolution through scientific means and the Darwinian and neo-Darwinian theory of biological evolution. I argue that, due to such gap, the transhumanist programme is flawed and requires a new and better understanding of biological mechanisms in order to attain its goals.
\end{abstract}

Keywords: Charles Darwin, Theory of Evolution, transhumanism, Nick Bostrom, procreative beneficence

Doi: 10.14746/eip.2014.2.8 